\title{
Efectos de la globalización financiera en la administración y regulación de riesgos bancarios en México ${ }^{1}$
}

\author{
Antonio Ruiz Porras* \\ Noemí Vásquez Quevedo** \\ José Antonio Núñez Mora***
}

\section{Resumen}

En este artículo investigamos los efectos de la globalización financiera en la administración bancaria en México. Así, evaluamos cómo cambiaron las prácticas de administración bancaria tras la compra de bancos mexicanos por la banca internacional y tras la adopción de estándares contables internacionales y los de Basilea II. Los hallazgos de esta investigación sugieren que es dificil evaluar a priori los efectos de la globalización financiera en la administración bancaria con base en la teoría y evidencia internacional disponibles. Empíricamente, mostramos que la globalización trajo beneficios y costos concretos en México. Entre los beneficios destacan la mayor estabilidad sistémica, la mayor rentabilidad y eficiencia en los bancos y posiblemente mejores prácticas de autorización y cobro de créditos. Entre los costos encontramos la concentración de los bancos y la disminución del crédito privado para la vivienda y el comercio. Además, mostramos cómo la internacionalización de los bancos se reforzó como consecuencia de los cambios en la normatividad. Finalmente, sugerimos cómo podría evolucionar el sistema bancario mexicano en el corto plazo y señalamos algunos retos que deberá afrontar en la globalización financiera.

Palabras clave: bancos, México, administración de riesgos, regulación, globalización.

\footnotetext{
${ }^{1}$ Los autores reconocen y agradecen las valiosas sugerencias de los árbitros de la revista Contaduría y Administración. Asimismo, hacen extensivo dicho reconocimiento a los asistentes al X Foro de Investigación: Congreso Internacional en Contaduría, Administración e Informática (UNAM-FCA y ANFECA) y al III Congreso Internacional de Administración de Riesgos (Tecnológico de Monterrey, Campus Ciudad de México). Además, los autores agradecen la lectura cuidadosa de Nancy García Vázquez (FLACSO) a los borradores de este trabajo.

* Profesor del Departamento de Contabilidad y Finanzas, Tecnológico de Monterrey, campus Ciudad de México. Correo electrónico: ruiz.antonio@itesm.mx

**Directora del Departamento de Contabilidad y Finanzas, Tecnológico de Monterrey, campus Ciudad de México. Correo electrónico: nvasquez@itesm.mx

***Profesor del Departamento de Contabilidad y Finanzas, Tecnológico de Monterrey, campus Ciudad de México. Correo electrónico: janm@itesm.mx
} 
Antonio Ruiz Porras

Noemí Vásquez Quevedo

José Antonio Núñez Mora

\section{Introducción}

$\mathrm{E}$

n este artículo investigamos los efectos de la globalización financiera en la administración bancaria en México. ${ }^{2}$ Específicamente, evaluamos cómo cambiaron las prácticas de administración bancaria tras la compra de bancos mexicanos por la banca internacional y tras la adopción de los estándares contables internacionales (GAAP) y de Basilea II (BIS, 2004). Dichos cambios son analizados mediante la comparación de indicadores bancarios y mediante la comparación de los lineamientos internacionales y mexicanos de normatividad bancaria. Así, buscamos ofrecer elementos de reflexión y análisis en torno a la internacionalización de los sistemas financieros desde la perspectiva de las economías emergentes.

Este trabajo está motivado por inquietudes de política económico-financiera y de investigación académica: las primeras están dadas en función de evitar crisis bancarias sistémicas, como la ocurrida en México en 1995, pues —al igual que ahora- dicha crisis fue antecedida por cambios en la propiedad y regulación prevalecientes (véase Ortiz Martínez, 1994); las segundas, para entender mejor las actividades de administración de riesgo y los efectos de la regulación bancaria desde una perspectiva teórica y aplicada, debido a que existen controversias en torno a su impacto en las actividades de los intermediarios (véase Allen y Santomero, 1997; y Rose, 2003).

Nuestro trabajo amplía la literatura sobre los efectos de la globalización en la conducta y la regulación de los bancos. Sin embargo, a diferencia de otros estudios y análisis, aquí no nos centramos en las relaciones macroeconómicas entre globalización, crisis financieras y desarrollo económico. ${ }^{3}$ Nuestro énfasis se halla en los cambios en las prácticas de la administración bancaria institucional como consecuencia de la globalización. En este sentido, nuestro énfasis diverge

\footnotetext{
${ }^{2}$ En estricto sentido, los términos globalización y globalización financiera no tienen definición formal para economistas ni financieros. Nosotros definimos globalización financiera como "la reducción de las barreras al libre intercambio de bienes y servicios financieros y la mayor integración de los sistemas financieros nacionales". Esta definición extiende la dada por Stiglitz a la globalización en términos de "la supresión de las barreras al libre comercio y la mayor integración de las economías nacionales" (Stiglitz, 2002:11).

3 Entre éstos, destacan los trabajos y compilaciones en materia de globalización y crisis bancarias y financieras de Huerta (1998), Girón y Correa (2002), Girón y Chapoy (2005). En materia de globalización y desarrollo económico destacan los estudios de Girón (1992), Stiglitz (2002) y Mishkin (2005).
} 
Efectos de la globalización financiera en la administración

y regulación de riesgos bancarios en México

de los tradicionales estudios empíricos que analizan los efectos de la incursión de bancos extranjeros en los sistemas bancarios o los efectos de las regulaciones financieras, puesto que no asumen ninguna causalidad específica. ${ }^{4}$

Se puede considerar que nuestro trabajo complementa otros estudios hechos en México, particularmente en lo que concierne al estudio de Girón y Levy (2005) en torno a los efectos de la globalización. Este último trabajo se centra en las causas y efectos de la crisis financiera de 1994-1995 y en los efectos de la globalización en las políticas de financiamiento al desarrollo. Otros estudios que complementan al nuestro son los de Huerta (1998), Bubel y Skelton (2002) y BANXICO y SHCP (2003); estos últimos abordan los efectos de la globalización en la conducta de los bancos, sin considerar sus efectos en la normatividad institucional.

La globalización financiera y la administración bancaria ofrecen una amplia gama de posibilidades y ángulos de análisis. Por esta razón aquí planteamos una serie de preguntas que orientan y definen esta investigación: ¿cuáles son las prácticas de administración y regulación de riesgos bancarios más comunes en el nivel global?; ¿cuáles son los alcances y límites de la teoría y práctica de la administración bancaria?; ¿cuáles son los beneficios y costos de la globalización financiera en el sector bancario en México?; ¿cuáles son las perspectivas y retos del sistema bancario mexicano?

Los hallazgos de esta investigación sugieren que es difícil evaluar a priori los efectos de la globalización financiera en la administración bancaria con base en la teoría y evidencia internacional disponibles. Empíricamente, mostramos que la globalización trajo beneficios y costos concretos en México. Entre los beneficios destacan la mayor estabilidad sistémica, la mayor rentabilidad y eficiencia en los bancos y posiblemente mejores prácticas de autorización y cobro de créditos; entre los costos encontramos la concentración de los bancos y la disminución del crédito privado para la vivienda y el comercio. Además, mostramos cómo la internacionalización del sistema bancario se reforzó como consecuencia de los cambios en la normatividad.

4 Véase Claessens, Demirguc-Kunt y Huizinga (2001); Claessens y Laeven (2003); y Ruiz Porras (2006) para algunos estudios econométricos en torno a la conducta de los bancos. En lo que se refiere a estudios sobre regulación bancaria veáse Goodhart et al. (1998) y Demirguc-Kunt, Laeven y Levine (2004). En el contexto de las economías emergentes, y en particular del contexto latinoamericano, véanse los trabajos de Rojas-Suárez (2001a) y (2001b) y Stellings y Studart (2003). 
Antonio Ruiz Porras

Noemí Vásquez Quevedo

José Antonio Núñez Mora

El artículo está dividido en seis secciones. La siguiente sección enmarca el análisis de la administración bancaria centrándose en sus alcances y limitaciones desde el punto de vista teórico. La tercera describe las prácticas de regulación financiera y de administración de riesgos en el entorno internacional. La cuarta analiza cómo la banca internacional ha influido en las prácticas de administración de riesgos y sus efectos sobre el sistema bancario mexicano. La quinta se centra en la forma en que los lineamientos de Basilea II han influido la regulación reciente en México. Finalmente, la última sección presenta las conclusiones y señala algunos retos que deberá afrontar el sistema bancario mexicano en la globalización financiera.

\section{Alcances y limitaciones de la administración bancaria}

El análisis de la administración bancaria está dividido en el estudio de las decisiones de administración de riesgos y en el de las regulaciones bancarias (Heffernan, 1996). Esta división, sólo por conveniencia práctica, es útil para diferenciar entre los determinantes y objetivos internos y externos a la conducta de los bancos. En ambos casos, se busca entender o manipular la conducta de los bancos a fin de satisfacer objetivos de interés privado y público. ${ }^{5}$ Esta situación explica que ambos tipos de análisis sean complementarios e igualmente relevantes en la administración bancaria. En ambos casos las decisiones de administración determinan el desempeño de los intermediarios.

Las decisiones de administración bancaria están ligadas a consideraciones sobre liquidez, activos, pasivos y capital de los intermediarios bancarios. ${ }^{6}$ Específicamente, la administración de riesgos juega el papel central cuando los intermediarios toman decisiones para realizar sus funciones en el mercado bancario; mientras que la regulación influye directamente en el mercado para que los bancos manejen sus riesgos de manera prudente. En ambos casos, el concepto de riesgo resulta fundamental. De hecho, la esencia de las actividades bancarias está asociada al manejo de riesgos (Freixas y Rochet, 1997); por lo tanto, la administración bancaria está en función del manejo de riesgos.

\footnotetext{
5 Los objetivos privados incluyen el maximizar las ganancias del banco y el valor agregado de los valores de sus accionistas; por su parte, los objetivos públicos de la banca incluyen el garantizar la operación eficiente y estable del sistema bancario.

6 Véase Mishkin (2004) y Freixas y Rochet (1997) para una introducción básica y avanzada, respectivamente, a estos temas.
} 
Efectos de la globalización financiera en la administración

y regulación de riesgos bancarios en México

Existe una gran variedad de riesgos que enfrentan las instituciones y reguladores bancarios en los niveles micro y macrofinanciero. ${ }^{7}$ Ello hace que el estudio del riesgo y sus efectos sea del mayor interés en la industria. Incluso hay consenso en torno a la necesidad de profundizar la investigación teórico-práctica en torno a estos temas (Allen y Santomero, 1997; Scholtens y van Wensveen, 2000). La creciente frecuencia de las crisis financieras justifica dicho consenso. ${ }^{8}$ Así, se han desarrollado herramientas operativas y modelos para que los intermediarios enfrenten riesgo; ${ }^{9}$ sin embargo, es aceptado que se requieren más análisis de cómo la gestión de riesgos influye en las actividades de los intermediarios.

La justificación de la racionalidad de las prácticas de administración de riesgo se suele asociar al trabajo de Modigliani y Miller (1958), el cual muestra que el valor de una empresa es independiente de cómo maneja su riesgo financiero en una economía con mercados perfectos, sin costos de bancarrota y sin impuestos. La administración de riesgo importa cuando estas condiciones no se cumplen; esto justifica que los modelos institucionales de administración de riesgos asuman que estas condiciones no se cumplen. Sin embargo, es justo reconocer que esta teoría dista todavía de explicar de manera satisfactoria la conducta de los intermediarios. ${ }^{10}$

Esta insatisfacción teórica puede extenderse hacia las prácticas de regulación bancaria. Si bien la justificación de dichas prácticas es asociada a que los problemas bancarios tienen repercusiones en los niveles privado y social, este argumento no tiene bases sólidas en la teoría de la intermediación (Dowd, 1996); incluso el empeoramiento de los problemas bancarios es atribuido a los esfuerzos por regular (Benston y Kaufman, 1996). En esta discusión están implícitas ciertas ideas y creencias acerca de los efectos reales de la regulación; sin embargo, resulta importante hacer notar que en la práctica no existen consensos acerca de sus efectos sobre las instituciones bancarias (Rose, 2003).

7 Riesgos inherentes al manejo de depósitos, portafolios de inversión y operaciones fuera de balance (cuentas de orden) son ejemplos de riesgos micro. Los riesgos macrofinancieros están asociados a la fragilidad de las instituciones bancarias y a la estabilidad del sistema de pagos en su conjunto.

8 Existen diversos estudios que han documentado el crecimiento de las crisis bancarias en el nivel mundial. Solamente entre 1975 y 1999 hay documentados 113 casos de crisis bancarias sistémicas en 93 países y otras 50 crisis menores en otros 44 (Caprio y Klingebiel, 2002). Esta situación explica la creciente importancia de la investigación referida a los determinantes de dichas crisis. Análisis destacados son los trabajos macroeconómicos de Kaminsky y Reinhart (1998) y Demirguc-Kunt y Detragiache (1998). Véase Ruiz Porras (2006) para un análisis en torno a los efectos de la estructura financiera en la incidencia de crisis bancarias.

9 Bessis (2002) ofrece una amplia exposición de estos temas.

${ }^{10}$ Véase Hunter y Smith (2002) para una introducción a los modelos institucionales de administración de riesgo. 
Antonio Ruiz Porras

Noemí Vásquez Quevedo

José Antonio Núñez Mora

Lo anterior pone de manifiesto la dificultad de evaluar experiencias de administración bancaria con base en la teoría disponible. En el nivel internacional existen elementos que complican la evaluación (Krugman y Obsfeldt, 2003). En lo que se refiere a la administración de riesgos, estos elementos están referidos tanto a la inexistencia de seguros de depósito en el nivel internacional, así como de requisitos de reserva en las operaciones bancarias internacionales. Por lo que respecta a la regulación, estos elementos están referidos a la incertidumbre sobre quién o quiénes deben ejercer responsabilidades de regulador, supervisor y prestamista de última instancia para los bancos internacionales. Estos elementos incrementan los riesgos bancarios.

Esta situación contribuye a explicar el crecimiento de las quiebras bancarias en función de la internacionalización de los mercados bancarios. Aunque es cierto que el desarrollo tecnológico, la expansión geográfica y los procesos de consolidación hacen a los bancos internacionales menos vulnerables ante los diversos contextos económicos locales, se requieren mejores prácticas de administración bancaria para reducir los riesgos de solvencia. La mayor competencia entre los intermediarios, las diferencias económico-jurídicas locales y los distintos grados de volatilidad sugieren nuevas áreas de oportunidad para desarrollar la teoría y práctica de la administración bancaria.

\section{Administración y regulación de riesgos bancarios en el nivel internacional}

La evaluación de las prácticas de administración bancaria requiere del entendimiento de cómo funcionan los sistemas bancarios en el nivel internacional. Este conocimiento es necesario para contextualizar la naturaleza y generalidad de dichas prácticas. Por ello, resulta interesante hacer notar que si bien existen consensos acerca de cuáles debieran ser los objetivos deseables de la administración bancaria ${ }^{11}$, en realidad no hay consensos en cuanto a sus instrumentos y objetivos específicos. El análisis comparativo muestra que existen pocos consensos. Esto como consecuencia de la relativa autarquía de los sistemas bancarios en el nivel global.

11 La maximización de beneficios, la asignación de recursos y evitar problemas en el sistema financiero. 
Efectos de la globalización financiera en la administración

y regulación de riesgos bancarios en México

Los estudios para analizar las prácticas específicas de administración bancaria en un contexto internacional son escasos. ${ }^{12}$ Actualmente, el análisis de Barth, Caprio y Levine (2001a) —efectuado a instancias del Banco Mundial- es el más completo, en él se comparan las prácticas de administración y regulación existentes usando datos basados en cuestionarios hechos a reguladores, autoridades internacionales y bancos de 107 países. ${ }^{13}$ En el cuadro 1 se incluyen algunas de las preguntas y respuestas hechas con el fin de mostrar la naturaleza de las prácticas de administración de riesgo y regulación financiera alrededor del mundo.

\section{Cuadro 1}

Administración y regulación de riesgos bancarios alrededor del mundo

\begin{tabular}{|c|c|c|}
\hline PREGUNTA & $\begin{array}{c}\text { SÍ } \\
\text { (PAÍSES) } \\
\end{array}$ & $\begin{array}{c}\text { NO } \\
\text { (PAÍSES) } \\
\end{array}$ \\
\hline $\begin{array}{l}\text { ¿La proporción mínima capital/activo está de acuerdo con la directriz } \\
\text { de Basilea? }\end{array}$ & 100 & 7 \\
\hline ¿La proporción mínima capital/activo varía con el riesgo de mercado? & 24 & 81 \\
\hline $\begin{array}{l}\text { ¿El valor de las pérdidas por préstamos se deduce del capital de } \\
\text { préstamos? }\end{array}$ & 57 & 47 \\
\hline $\begin{array}{l}\text { ¿Las pérdidas inadvertidas en el portafolio de activos son deducidas } \\
\text { del capital contable reportado? }\end{array}$ & 60 & 44 \\
\hline $\begin{array}{l}\text { ¿Las pérdidas de tipo de cambio inadvertidas son deducidas del capital } \\
\text { contable reportado? }\end{array}$ & 62 & 40 \\
\hline $\begin{array}{l}\text { ¿Las regulaciones, concernientes a las provisiones iniciales y } \\
\text { subsecuentes de capital, pueden incluir otros activos distintos a dinero } \\
\text { en efectivo o a instrumentos del gobierno? }\end{array}$ & 45 & 57 \\
\hline ¿Pueden las provisiones iniciales de capital basarse en préstamos? & 34 & 67 \\
\hline $\begin{array}{l}\text { ¿Son las fuentes de fondos que son consideradas como capital regulado } \\
\text { verificadas por las autoridades reguladoras o autoridades supervisoras? }\end{array}$ & 86 & 19 \\
\hline $\begin{array}{l}\text { ¿Existen directrices explícitas, verificables y cuantificables para la } \\
\text { diversificación de activos? }\end{array}$ & 38 & 69 \\
\hline ¿Se prohíbe a los bancos hacer préstamos al extranjero? & 15 & 91 \\
\hline ¿Existe un requerimiento mínimo de liquidez? & 77 & 26 \\
\hline
\end{tabular}

Fuente: Elaboración propia con base en Barth, Caprio y Levine (2001a)

12 Estudios representativos son los de Nigh, Cho y Krishnan (1986), Zimmer y McCauley (1991) y Hirtle (1991).

${ }^{13}$ La base de datos compara los requerimientos y poderes de regulación en lo que concierne a requisitos de entrada, propiedad, capital, actividades permitidas, auditoría, organización, liquidez, transparencia de información, incentivos para supervisores, aseguramiento de depósitos y de disciplina bancaria. Esta base de datos se encuentra disponible en el sitio del Banco Mundial (http://www.worldbank.org). 
Antonio Ruiz Porras

Noemí Vásquez Quevedo

José Antonio Núñez Mora

El cuadro 1 muestra que no existen prácticas de administración ni de regulación comunes en el mundo. ${ }^{14}$ En la mayoría de las economías, los bancos no ajustan las mínimas proporciones capital/activo de acuerdo con los riesgos de mercado, ni los reguladores explicitan las directrices con respecto a la diversificación de activos que deben efectuar las instituciones bancarias. Lo anterior es especialmente relevante debido a que el capital bancario reduce las posibilidades de que los bancos se vuelvan insolventes bajo condiciones adversas, mientras que la diversificación de activos reduce los riesgos asociados a las actividades de otorgar préstamos e invertir.

Barth, Caprio y Levine (2001a) muestran que existen tendencias en la administración bancaria de acuerdo con el nivel de ingreso de los países. En lo que se refiere a las prácticas de supervisión, ellos notan que las restricciones hacia las actividades bancarias bajan y el nivel de monitoreo sube conforme el nivel de ingreso aumenta; también indican que la severidad de los requerimientos de capital y de evaluación de préstamos son menores en países con menor ingreso, mientras lo contrario ocurre en lo concerniente a las exigencias de aprovisionamiento; además, muestran que el número de supervisores por banco es más de tres veces mayor en los países en vías de desarrollo que en los países desarrollados. ${ }^{15}$

En un estudio posterior (2001b), estos mismos autores sugieren que hay ciertas prácticas que promueven el desempeño bancario y la estabilidad bancaria; específicamente, incluyen prácticas que obligan a transparentar información, que fortalecen el control privado de los bancos, y que dan incentivos a los agentes privados para ejercer el control corporativo de los bancos. Más aún, ellos señalan que aquellas prácticas que transparentan la información financiera y que limitan los incentivos para ejercer acciones que impliquen riesgo moral mejoran el desempeño y la estabilidad bancarios.

Demirguc-Kunt, Laeven y Levine (2004) analizan el impacto de regulaciones, la estructura de mercado y las instituciones nacionales en los márgenes netos bancarios y los costos. Su estudio econométrico muestra que regulaciones inflexibles

\footnotetext{
${ }^{14}$ Excepto en lo que se refiere a la mínima proporción capital/activo dictada por el Comité de Basilea y en la necesidad de tener provisiones de liquidez.

15 Sin embargo, ellos notan que en las economías en desarrollo este número está asociado con una mayor dependencia política de las autoridades supervisoras.
} 
Efectos de la globalización financiera en la administración

y regulación de riesgos bancarios en México

en torno a la entrada de bancos y a las actividades bancarias incrementan el costo de la intermediación financiera; asimismo, muestran que la concentración bancaria no está asociada a los márgenes netos bancarios cuando se controlan los impedimentos regulatorios hacia la competencia y la inflación, razón por la cual ellos concluyen que las regulaciones bancarias reflejan amplios enfoques nacionales hacia lo que son la propiedad privada y la competencia.

El escrito más conocido acerca de los efectos de la globalización en el sector bancario es el de Stiglitz (2004), quien — en su análisis — sugiere que la competencia global en el sector bancario tenderá a estandarizar las prácticas de administración de riesgos en el nivel mundial. ${ }^{16}$ Sin embargo, en virtud del papel jugado por los bancos estadounidenses en alimentar burbujas especulativas, este autor aboga por la imposición de reglamentaciones y transparencia en las instituciones en el nivel global con el fin de mitigar potenciales conflictos de intereses e incentivos perversos. Para Stiglitz los efectos de la globalización dependen fundamentalmente de cómo sea manejada ésta.

Los estudios anteriores sugieren que los efectos de la globalización bancaria en sistemas bancarios específicos no pueden determinarse a priori porque las prácticas de administración y regulación de riesgos bancarios en el nivel internacional dependen del contexto regulador local y del grado de desarrollo de las economías. No obstante, también sugieren que en un contexto global mientras se promuevan una mayor transparencia en la información y una regulación tendiente a reducir conflictos de intereses, el desempeño bancario y la estabilidad bancaria serán favorecidos. Lo anterior sugiere que estándares contables adecuados podrían ser útiles para evaluar los efectos de la globalización. ${ }^{17}$

${ }^{16}$ En este sentido, el autor señala que "inevitablemente otros países tendrán que alterar sus normas y sus prácticas. No es preciso que se sometan a las normas y prácticas empresariales estadounidenses, pero tampoco pueden pasarlas por alto" (Stiglitz, 2004:214).

17 Hasta donde sabemos, no existen bases de datos de acceso público con información contable comparable en el nivel internacional que nos pudieran servir para diferenciar el desempeño de instituciones locales y extranjeras en contextos económicos específicos. Sin embargo, desde hace unos diez años, el Banco Mundial ha hecho esfuerzos para recolectar y hacer disponible información financiera y bancaria agregada con fines de investigación. 
Antonio Ruiz Porras

Noemí Vásquez Quevedo

José Antonio Núñez Mora

\section{Banca extranjera y administración bancaria en México}

La internacionalización del sector financiero y la banca mexicanos es relativamente reciente. En la práctica, dicha internacionalización se manifestó tras la crisis financiera de 1994-95 como parte de una estrategia para reorganizar y sanear al sistema financiero; en el sector bancario, dicha estrategia se justificó en términos del aseguramiento de los depósitos del público y de la recapitalización de los bancos; asimismo, permitió —entre otras medidas - el rescate de los bancos y el cambio y retiro de las concesiones de propiedad de los intermediarios. Así, la estrategia eliminó restricciones sobre los derechos de propiedad; además, permitió realizar fusiones y operaciones de compraventa de los bancos existentes.

La autorización de bancos extranjeros conllevó a un cambio del régimen de propiedad de la banca mexicana. ${ }^{18}$ De esta forma, en diciembre de 1996 — justo antes de que la nueva regulación sobre la propiedad extranjera entrara en vigor- sólo $7 \%$ de los activos totales de la banca en México eran controlados por extranjeros (Haber y Kantor, 2003). En marzo de 1997, el 14\% de los activos de los bancos estaban controlados por bancos extranjeros. Actualmente, 19 de 32 bancos son de propiedad extranjera; aquí se incluyen a los bancos más grandes del sistema bancario mexicano: Bancomer, Banamex y Banca Serfin. El cuadro 2 muestra como los bancos extranjeros adquirieron las instituciones del sistema bancario mexicano.

${ }^{18}$ Una creencia común es que la firma del Tratado de Libre Comercio de América del Norte (NAFTA por sus siglas en inglés) permitió el establecimiento inmediato de bancos internacionales y la libre adquisición de bancos mexicanos por la banca extranjera. En realidad, el NAFTA (capítulo XIV Anexo 1413.6) especificaba límites explícitos a la propiedad y participación de la banca extranjera a fin de salvaguardar el sistema de pagos de México; más aún, establecía plazos y mecanismos para restringir a los intermediarios extranjeros. Sin embargo, estas restricciones fueron rebasadas en la práctica. 
Efectos de la globalización financiera en la administración

y regulación de riesgos bancarios en México

\section{Cuadro 2}

Cronología de adquisiciones bancarias en México

\begin{tabular}{|c|c|c|}
\hline FECHA & BANCO EXTRANJERO & BANCO NACIONAL \\
\hline Mayo 30, 1995 & Banco Bilbao-Vizcaya & Banco Mercantil Probursa \\
\hline Agosto 9, 1996 & BBVA & $\begin{array}{c}\text { Banca Cremi } \\
\text { y Banco Oriente }\end{array}$ \\
\hline Marzo 18, 1997 & $\begin{array}{l}\text { Honk Kong Shangai Bank } \\
\text { (HSBC) }\end{array}$ & Grupo Financiero Serfin \\
\hline Mayo 16, 1997 & Banco Santander & $\begin{array}{c}\text { InverMexico } \\
\text { y Banco Mexicano }\end{array}$ \\
\hline Agosto 27, 1997 & Citibank & Banca Confia \\
\hline Мayo 8, 1997 & Santander & $\begin{array}{c}\text { Grupo Financiero } \\
\text { Serfin }\end{array}$ \\
\hline Marzo 30, 2000 & Nova Scotia Bank & Grupo Financiero Inverlat \\
\hline Junio 29,2000 & BBVA & Bancomer \\
\hline Mayo 17, 2001 & Citibank & Banamex \\
\hline Diciembre, 2002 & HSBC & Bital \\
\hline
\end{tabular}

Fuente: Elaboración propia con base en Bubel y Skelton (2002)

y http://woodstockinst.org

Paralelamente a los cambios de propiedad, se emitieron nuevas reglas contables (enero 1997) que modificaron y redefinieron los conceptos de cartera vencida y préstamo; introdujeron la valoración de mercado a mercado; y tomaron en cuenta los efectos de la inflación en la contabilidad bancaria. La base de dichas reglas estaba en los principios internacionales generalmente aceptados (GAAP, por sus siglas en inglés). Así, se trató de proveer información clara y oportuna a los mercados. Creemos que estas reglas contribuyeron a acelerar la internacionalización de las prácticas de administración bancaria en México porque permitieron comparar a los bancos nacionales con sus contrapartes internacionales.

Analíticamente, los efectos de la globalización financiera se pueden estudiar mediante indicadores contables y financieros. Aquí usamos indicadores de concentración y solvencia sistémicos, de rentabilidad y eficiencia y de crédito y default para evaluar dichos efectos. Específicamente, usamos los primeros dos tipos de 
indicadores para analizar la estructura de mercado y la capitalización del sistema bancario. Los siguientes dos los empleamos para analizar el desempeño financiero de las instituciones bancarias. Finalmente, los últimos dos los usamos para analizar el manejo del crédito.

Económicamente, el análisis de la estructura de mercado y la capitalización están relacionados con la competencia y la estabilidad en el sistema bancario. Particularmente, el estudio de la estructura lo hacemos mediante índices Herfindal para activos y capital bancarios. ${ }^{19}$ El estudio de la estabilidad lo hacemos con proporciones de capital sobre activos. Así, con base en estos indicadores económicos, encontramos que el sistema bancario se ha concentrado y capitalizado entre 1998 y 2003 (véase figura 1). Esta conclusión sugiere que el sistema bancario ganó mayor estabilidad sistémica al precio de una menor competencia entre las instituciones bancarias. ${ }^{20}$

El estudio del desempeño financiero de los intermediarios lo hacemos mediante indicadores de utilidades y de operación bancarios. Concretamente, el análisis de utilidades lo hacemos mediante la estimación del margen financiero y de interés total, mientras que el análisis de operación lo hacemos con proporciones de costos de administración sobre activos. En virtud de lo anterior, usualmente se asocia la entrada de la banca extranjera con cambios en la eficiencia; los indicadores

19 El índice Herfindal es un índice de concentración del mercado que oscila en el rango $(0,1)$. En tanto mayor sea el valor de este índice, el mercado tenderá a ser mayormente concentrado (con el monopolio como caso límite). Analíticamente se determina calculando primeramente la proporción de activos (o capital) de cada banco $i$ en el sistema en un tiempo determinado $t, A_{i t}$, respecto al total de activos del sistema
Esta proporción se eleva al cuadrado y se suma para todos los bancos. $A_{i, t}$. Matemáticamente, este índice se expresa como: $H_{t}=\sum_{i}\left(\frac{A_{i, t}}{\sum_{i} A_{i, t}}\right)^{2}$

20 Es importante señalar que esta conclusión acerca de los efectos de competencia en la estabilidad bancaria es debatible porque existen cuestionamientos en torno al uso de indicadores de concentración como indicadores de competencia. Sin embargo, la idea de que la concentración bancaria incrementa la estabilidad de los sistemas bancarios ha sido apoyada por otros estudios (véase Beck, Demirguc-Kunt y Levine, 2003). 
Efectos de la globalización financiera en la administración

y regulación de riesgos bancarios en México

Figura 1

Indicadores de concentración y solvencia bancarios
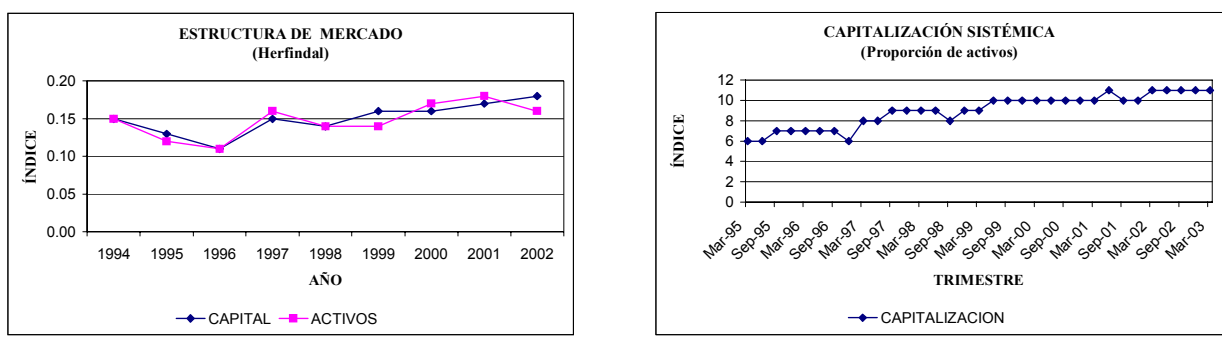

Fuente: Elaboración propia con base en datos de CNBV, Haber y Kantor (2003)

de operación los dividimos de acuerdo con el régimen de propiedad. De esta forma, calculamos índices para bancos domésticos, para bancos extranjeros con bancos fusionados y adquiridos y para bancos extranjeros de nuevo ingreso.

El análisis de los indicadores muestra que la rentabilidad y operación bancarias crecieron en un primer momento, para luego estabilizarse (véase figura 2). Específicamente, los márgenes de utilidades pasaron de valores negativos a positivos a partir de 1998. Paralelamente, los costos de administración tendieron a disminuir. Más aún, los indicadores confirman que un mayor grado de penetración de la banca extranjera está asociado a menores costos; por ello, los indicadores sugieren que como resultado del cambio en las normas contables y la inserción de la banca extranjera la rentabilidad y eficiencia de los bancos tendieron a incrementarse y estabilizarse entre 1995 y 2003.

El manejo del crédito lo analizamos mediante indicadores de otorgamiento de crédito y morosidad bancarios. En lo que se refiere a los primeros, nos centramos en aquéllos para el sector privado, diferenciando entre créditos comerciales, de consumo, para la vivienda y reestructurados para observar el proceso de 
Figura 2

Indicadores de rentabilidad y operación bancarios
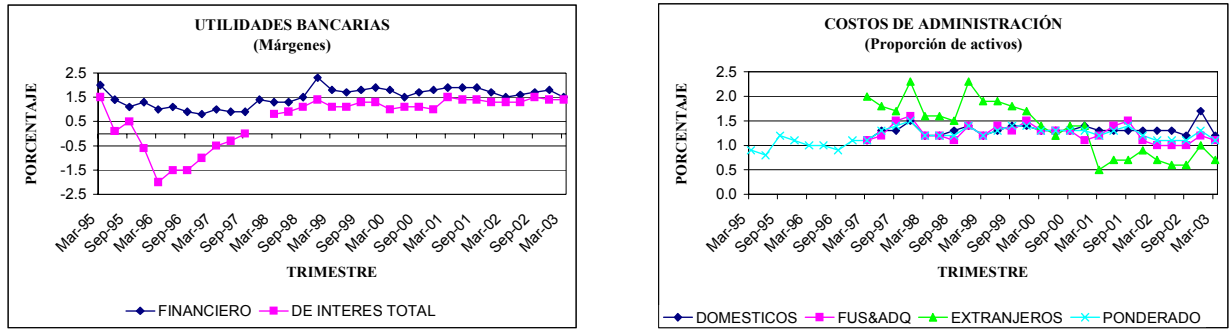

Fuente: Elaboración propia con base en datos de CNBV, Haber y Kantor (2003)

canalización de los pasivos bancarios. En relación con los indicadores de morosidad, diferenciamos entre los indicadores de cartera vencida, redescontada y reestructurada, con el objeto de percibir los efectos de las normas contables para el cobro y autorización de créditos. ${ }^{21}$

Los indicadores muestran que el crédito bancario al sector privado y los problemas de cartera disminuyeron tras la internacionalización de la banca mexicana. Esto es importante porque los orígenes de la crisis bancaria de 1994-95 se encuentran en políticas inapropiadas de expansión de crédito y en reglas contables inadecuadas. Los indicadores muestran que las proporciones de crédito comercial a la vivienda y los problemas de cartera disminuyeron a partir de 1998 (véase figura 3), razón por la cual el análisis sugiere que los niveles de ineficiencia han disminuido a costa de reducir el crédito productivo vía financiamientos al consumo. ${ }^{22}$ Una implicación asociada es que los bancos mexicanos son relativamente más aversos al riesgo de largo plazo.

${ }^{21}$ Antes de la aplicación de las reglas contables basadas en las prácticas internacionales, los estados contables mexicanos subestimaban la magnitud de los problemas de morosidad en virtud de que los antiguos estándares contemplaban que, cuando un crédito estaba vencido, sólo los intereses de éste eran contabilizados como vencidos y se excluía el monto del principal. Por comparación, las normas de contabilidad internacionales estipulaban que cuando un crédito tuviera un plazo de 90 días de antigüedad, tanto el valor del principal como el del interés se declaraban como cartera vencida.

${ }^{22}$ Esta conclusión complementa los estudios de otros autores, quienes concluyen que el valor real del crédito bancario total ha disminuido (Haber y Kantor, 2003). 
Efectos de la globalización financiera en la administración

y regulación de riesgos bancarios en México

Figura 3

Indicadores de crédito y default bancarios
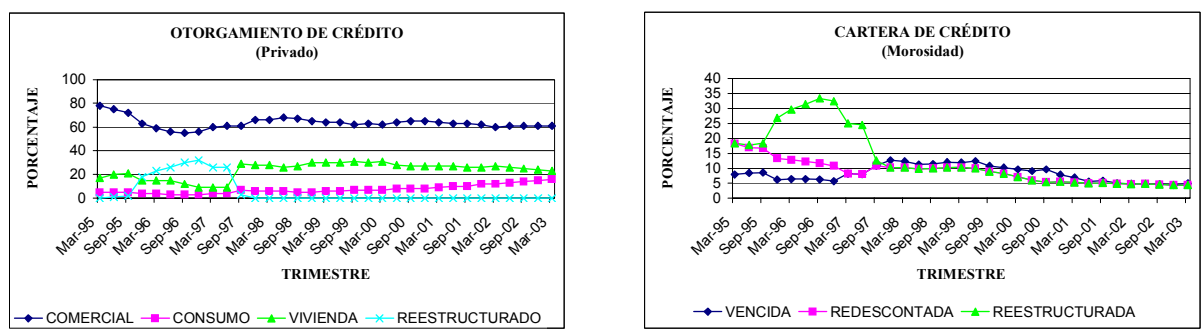

Fuente: Elaboración propia con base en datos de CNBV, Haber y Kantor (2003)

Concluimos indicando que los datos sugieren que la administración de riesgos bancarios en México se modificó como consecuencia de los cambios en los regímenes de propiedad y contable de la banca. En este sentido, la globalización financiera trajo beneficios y costos para la economía mexicana. Los beneficios pueden resumirse en una mayor estabilidad sistémica, una mayor rentabilidad y eficiencia en los bancos y posiblemente en mejores prácticas de autorización y cobro de créditos. Sin embargo, esto ha conllevado costos como una mayor concentración de los bancos (y quizá un mayor poder de mercado) y la disminución del crédito privado para las actividades comerciales y de vivienda (y una relativa aversión a los riesgos de largo plazo).

\section{Basilea II y sus efectos en la administración bancaria}

En México, las prácticas de regulación y administración de riesgos se diferencian de acuerdo con la naturaleza de las actividades de intermediación financiera. Esto no ocurre en el nivel internacional porque no existen reguladores globales y los intermediarios internacionales son muy diversos. La diferenciación existente en México busca que los intermediarios desempeñen sus funciones de manera especializada a fin de garantizar la estabilidad y funcionamiento del sistema financiero. Esto justifica que existan prácticas institucionales y normativas específicas tanto para intermediarios bancarios como no bancarios, además de prácticas comunes a todas las instituciones (véase cuadro 3). 
Antonio Ruiz Porras

Noemí Vásquez Quevedo

José Antonio Núñez Mora

Cuadro 3

Regulación y administración de riesgos en México

\begin{tabular}{|c|c|c|}
\hline Tipo de institución & $\begin{array}{c}\text { Circular en materia de } \\
\text { administración de riesgos }\end{array}$ & Emitida por \\
\hline Banca Múltiple & 1423 & CNBV \\
\hline Banca de Desarrollo & 1473 & CNBV \\
\hline Casas de Bolsa & $10-247$ & CNBV \\
\hline Aseguradoras & S-11.6 & CNSF \\
\hline Afores & $51-1$ & CONSAR \\
\hline Todas & $\begin{array}{c}\text { 31 puntos de Banxico para } \\
\text { operar derivados }\end{array}$ & \\
\hline
\end{tabular}

Fuente: KPMG (2005)

La administración bancaria en México depende de las prácticas internacionales en cuanto a su definición y desarrollo; esto ha sido particularmente evidente tras la crisis económico-financiera de 1994-1995. Puede decirse que la globalización del sistema bancario mexicano, en un nivel regulatorio, comenzó con la adopción en 1994 de las recomendaciones del Comité de Basilea de 1988. ${ }^{23}$ Técnicamente esto fijó un estándar internacional para medir la solvencia y desempeño de las instituciones bancarias mexicanas; sin embargo, esto no fue suficiente para dimensionar y reducir los problemas del sistema bancario que se manifestarían en 1995; los orígenes de estos problemas estuvieron en la privatización bancaria efectuada pocos años atrás. ${ }^{24}$

En el nivel internacional, la aparición de nuevos instrumentos financieros y el incremento de las posiciones de riesgo en los mercados hicieron necesario un mejor manejo de riesgos durante los noventa. Esta situación hizo que las reglas

${ }^{23}$ El Comité de Basilea es un comité de autoridades de supervisión bancaria conformado por los gobernadores de los bancos centrales de los países del G-10 más Luxemburgo y Suiza. Su actividad primordial consiste en evaluar y analizar aquellas regulaciones concernientes al ámbito de las operaciones bancarias internacionales en los países miembros para evitar que las operaciones bancarias internacionales escapen de una supervisión efectiva. En los ochenta, el comité intentó establecer un conjunto de estándares de adecuación de capital para evitar quiebras bancarias (Acuerdo de Basilea de 1988). Específicamente, estos estándares indicaban que cada banco debía respaldar sus activos con el $8 \%$ de su capital y que un banco podía perder como máximo un $4 \%$ de core capital como proporción de sus activos. Véase Heffernan (1996).

${ }^{24}$ Haber y Kantor (2003), entre otros autores, localizan los orígenes de los problemas de 1994-95 en cómo se privatizó la banca a principios de los años noventa. Véase Ortiz Martínez (1994) para una descripción de cómo se llevó a cabo dicho proceso desde la perspectiva de las autoridades responsables. 
Efectos de la globalización financiera en la administración

y regulación de riesgos bancarios en México

del Comité de Basilea de 1988 se volvieran obsoletas para garantizar la solvencia de las instituciones bancarias y se hizo indispensable crear un nuevo acuerdo para calcular el capital regulatorio. Este acuerdo (conocido como Basilea II) inicialmente tenía un carácter regional y normativo de la regulación..$^{25}$ Sin embargo, en la práctica, sus lineamientos de regulación han alcanzado una dimensión global. ${ }^{26}$

Actualmente, las prácticas de administración y regulación de riesgos bancarios son influidas por los lineamientos de Basilea II. Dichos lineamientos son reconocidos por más de 130 países, además del FMI y el Banco Mundial como buenas prácticas. ${ }^{27}$ En virtud de que los bancos internacionales concentran la propiedad de los bancos y que los cambios en la regulación mexicana siguen los lineamientos de Basilea II, no creemos que la transición habrá de repercutir negativamente en el sistema bancario mexicano. De hecho, la normatividad mexicana sigue muy de cerca en cuanto a tiempos y formas a los lineamientos suizos (véase cuadro 4).

${ }^{25}$ En BIS (2004) se encuentran los lineamientos de Basilea II.

${ }^{26}$ Basilea II tiene tres objetivos genéricos. El primero consiste en conseguir que los requerimientos de capital de los bancos sean sensibles al riesgo. El segundo remarca que no es suficiente el establecimiento de una exigencia mínima de capital para garantizar su adecuación al perfil de riesgo real de las entidades bancarias, razón por la cual busca que las herramientas, sistemas y procedimientos de gestión del riesgo, aunados a la propia disciplina de mercado contribuyan a establecer los requerimientos de capital efectivo. Por último, el tercer objetivo consiste en lograr una mejora generalizada de los sistemas de medición y gestión del riesgo en la industria financiera (Méndez del Río, 2003).

${ }^{27}$ Sin embargo, es justo reconocer que existen interrogantes en el nivel institucional y operativo alrededor de los acuerdos de Basilea II. Véase Saidenberg y Schuermann (2003) para un compendio de los mismos. 
Antonio Ruiz Porras

Noemí Vásquez Quevedo

José Antonio Núñez Mora

\section{Cuadro 4}

Instrumentación de los Acuerdos de Basilea en México

\begin{tabular}{|c|c|c|c|}
\hline FECHA & BASILEA & MÉXICO & CONTENIDO \\
\hline Julio 1988 & $\begin{array}{l}\text { Acuerdo de } \\
\text { Capital }\end{array}$ & & $\begin{array}{l}\text { Medidas de capital y estándares de capitalización hacia una convergencia } \\
\text { internacional. }\end{array}$ \\
\hline Julio 1994 & & $\begin{array}{ll}\text { Reglas para los } \\
\text { requerimientos } & \text { de } \\
\text { Capitalización (SHCP) }\end{array}$ & $\begin{array}{l}\text { Esta regulación buscó asegurar cierto "capital regulatorio" que hiciera frente a } \\
\text { las obligaciones de la banca ante crisis económicas. }\end{array}$ \\
\hline Septiembre 1995 & & Circular 2019/95 & Presenta los 31 requerimientos para participar en los mercados de derivados y \\
\hline Junio 1999 & 1er. documento & (Banxico) & $\begin{array}{l}\text { busca minimizar riesgos de insolvencia y liquidez del sistema financiero. } \\
\text { Primer documento de consulta. El nuevo acuerdo de capital consiste en tres } \\
\text { pilares: requerimientos de capital mínimo, proceso de supervisión y uso efectivo } \\
\text { de disciplina de mercado. }\end{array}$ \\
\hline Noviembre 1999 & & Circular 1423 (CNBV) & $\begin{array}{l}\text { Disposiciones de carácter prudencial en materia de administración integral de } \\
\text { riesgos. }\end{array}$ \\
\hline Enero 2001 & 20. documento & & $\begin{array}{l}\text { Segundo documento de consulta. Se hace énfasis en las metodologías internas, a } \\
\text { la supervisión a la disciplina de mercado. Es más flexible e incentiva a una } \\
\text { mejor administración de riegos }\end{array}$ \\
\hline Febrero 2001 & & Circular 1480 (CNBV) & $\begin{array}{l}\text { Metodología que las instituciones de banca múltiple utilizan para la calificación } \\
\text { de su cartera crediticia. }\end{array}$ \\
\hline Octubre 2002 & 3er QIS & & $\begin{array}{l}\text { Orientación técnica del QIS } 3 \text { (quantitative impact studies) para estimar el } \\
\text { impacto que tendría el Nuevo Acuerdo en las carteras bancarias. }\end{array}$ \\
\hline Noviembre 2002 & & Circular $1506(\mathrm{CNBV})$ & Disposiciones de carácter prudencial en materia de control interno. \\
\hline Abril 2003 & 3er. documento & & $\begin{array}{l}\text { Tercer documento de consulta. Presenta recomendaciones para reforma en el } \\
\text { ámbito de regulación y supervisión del sistema financiero, dando más énfasis a } \\
\text { temas relacionados con la calidad de la gestión y la administración de los riesgos } \\
\text { bancarios. }\end{array}$ \\
\hline Junio 2004 & $\begin{array}{l}\text { Nuevo Acuerdo } \\
\text { de Capital o } \\
\text { Basilea II }\end{array}$ & & $\begin{array}{l}\text { El nuevo acuerdo introduce revisiones importantes en los enfoques para } \\
\text { medición y control no solo del riesgo de crédito, sino también de los riesgos } \\
\text { financieros o de mercado (liquidez, tasa de interés, tipo de cambio), así como de } \\
\text { los denominados operativos. Astmismo, enfatiza en la evaluación de las } \\
\text { políticas, procesos y procedimientos para la gestión de estos riesgos. }\end{array}$ \\
\hline Julio 2004 & & $\begin{array}{l}\text { Modificaciones C-1423 } \\
\text { (CNBV) }\end{array}$ & $\begin{array}{l}\text { Disposiciones de carácter prudencial en materia de administración integral de } \\
\text { riesgos. Lineamientos mínimos sobre administración integral de riesgos, y } \\
\text { mecanismos que permitan realizar actividades con niveles de riesgo acordes con } \\
\text { el capital neto y capacidad operativa. Otorgan mayor importancia al riesgo } \\
\text { operativo. Derogan la C- } 1423 \text {. }\end{array}$ \\
\hline
\end{tabular}

Fuente: Elaboración propia con base en CNBV, BIS, SHCP

La nueva normatividad mexicana busca reducir los problemas de asimetría de información y mejorar el manejo de riesgos. Específicamente, los problemas de información son enfrentados mediante la adopción de Sistemas de Acciones Correctivas Tempranas (Early Warning Systems) y el fomento a la disciplina de mercado. La adopción de estos sistemas pretende detectar y prevenir problemas de capitalización y solvencia de los bancos. ${ }^{28}$ Los cambios referidos a la disciplina de mercado buscan homologar la información y requisitos que deberán revelar y publicar los bancos para facilitar el análisis de su solvencia y su situación financiera. Esta normatividad mexicana (CNBV 2004a y 2004b) en materia de riesgos

${ }^{28}$ Existe una amplia literatura empírica relativa a los sistemas de prevención de crisis bancarias y de tipo de cambio. Véase Gaytan y Johnson (2002) para una revisión metodológica de los mismos en el sector bancario. 
Efectos de la globalización financiera en la administración

y regulación de riesgos bancarios en México

está de acuerdo con los pilares en los que se sustenta Basilea II. ${ }^{29}$ Específicamente, ésta indica que se realizarán procesos formales de identificación y recopilación de eventos de pérdida atribuibles al riesgo operativo. Esto con el fin de contar con series de tiempo que sirvan para analizar la importancia y recurrencia de dichos eventos mediante modelos financieros. En lo que se refiere al riesgo de crédito, la normatividad permite calificar la cartera en función del tipo de créditos que la conforman; asimismo, establece metodologías para definir estimaciones del riesgo y la posibilidad de utilizar metodologías internas a las instituciones.

La normatividad modificará la estructura del sistema financiero mexicano en el corto plazo. Muy probablemente los bancos tendrán que implantar un marco de administración de riesgos que vincule el capital regulatorio al capital económico. ${ }^{30}$ Asimismo, los clientes de los bancos afrontarán una nueva estructura de riesgos derivada de la mayor transparencia bancaria; con ello las agencias calificadoras ganarán prominencia, pero al costo de enfrentar una mayor competencia a la que ahora existe; además, es posible que las instituciones experimenten una tendencia hacia la bursatilización. Cabe señalar que en México la normatividad entrará completamente en vigor en junio de 2007.

Así concluimos indicando que la globalización del sistema bancario mexicano se reforzó mediante las prácticas de regulación que buscaron homologar la información bancaria mexicana con estándares internacionales para fines de comparación, análisis y supervisión de los intermediarios. Actualmente, la normatividad del sistema bancario busca mejorar el manejo de riesgos operativos y de crédito, fomentar la disciplina de mercado y el uso de Early-Warning Systems. En este sentido, el proceso quizá pudiera considerarse un éxito. El país está relativamente adelantado, en el nivel latinoamericano, en cuanto a la adopción de los lineamientos de Basilea II (Esparza, 2004).

${ }^{29}$ Basilea II está integrado por tres pilares: el pilar I establece una nueva metodología para el cálculo del capital con base en mejoras del proceso de medición y sensibilidad del riesgo; el pilar II propone mayores facultades para la autoridad a efecto de asegurar el seguimiento de sanas prácticas bancarias, una intervención oportuna y procurar requerimientos de capital superiores a los mínimos; el pilar III se enfoca en promover mejores estándares para la revelación de información, y la evaluación del capital que mantienen los bancos, proporcionando más elementos para que los ahorradores conozcan las fortalezas y debilidades de los intermediarios y puedan evaluar mejor con quién desean invertir.

${ }^{30}$ El capital económico es el capital relevante que se marca a mercado (mark-to-market) y representa el valor que se perdería o ganaría en una operación de compra-venta. 
Antonio Ruiz Porras

Noemí Vásquez Quevedo

José Antonio Núñez Mora

\section{Conclusiones y discusión}

En este artículo investigamos los efectos de la globalización financiera en la administración bancaria en México. Específicamente evaluamos cómo cambiaron las prácticas de administración bancaria en México tras la compra de los bancos mexicanos por la banca internacional y tras la adopción de estándares contables internacionales y la homologación de los lineamientos regulatorios de México con los de Basilea II. Así, hemos ofrecido una revisión de los efectos de la globalización financiera en las prácticas de administración y regulación de riesgos bancarios en México desde una panorámica teórica e internacional comparada.

Los hallazgos de este artículo se dividen en teóricos y empíricos. Teóricamente hemos mostrado que los efectos de la globalización en las prácticas de administración bancarias y en sistemas bancarios específicos no pueden determinarse a priori porque las prácticas de administración bancaria en el nivel internacional dependen del contexto regulador local y del grado de desarrollo de las economías; sin embargo, también mostramos que existen consensos alrededor de que es necesario desarrollar más investigación teórico-empírica acerca del riesgo y sus efectos en las actividades de los bancos. Asimismo, mostramos que existen consensos en torno a cómo fomentar desempeño y estabilidad bancarios basados en la transparencia y la existencia de regulaciones tendientes a reducir conflictos de intereses.

Empíricamente hemos demostrado que la globalización financiera en México se manifestó tras la crisis de 1994-95. Nuestros hallazgos sugieren que la globalización trajo beneficios y costos. Entre los primeros destacan una mayor estabilidad sistémica, una mayor rentabilidad y eficiencia en los bancos y posiblemente mejores prácticas de autorización y cobro de créditos; entre los segundos, la concentración de los bancos y la disminución del crédito privado para la vivienda y el comercio. Además, mostramos que la internacionalización del sistema bancario mexicano se reforzó mediante los cambios en la regulación, por lo que creemos que la administración de riesgos operativos y de crédito, así como la difusión de la información bancaria y la disciplina de mercado, serán más relevantes en el devenir bancario.

Nuestro análisis sugiere algunas ideas para desarrollar investigación. Estas ideas están referidas a cómo la administración de riesgos está vinculada con la estructura financiera y las estructuras de los mercados bancarios. A manera de 
Efectos de la globalización financiera en la administración

y regulación de riesgos bancarios en México

ilustración, adviértase que para el caso mexicano, la combinación de menores costos, mayor concentración y mayores proporciones de crédito al consumo sugiere que los beneficios de la globalización financiera serían de orden privado, mas no social, en virtud de que los usuarios de los servicios bancarios enfrentarían altos costos y porque el crédito existente no sería destinado a financiar el crecimiento económico. Otras ideas, que complementarían nuestro trabajo, estarían dadas en términos del análisis de los efectos de la globalización en cuanto a competitividad financiera y en cuanto a las formas de asignación de recursos y el financiamiento en México.

Finalmente, sólo nos resta indicar que si bien las prácticas de administración bancaria internacional pueden contribuir a que los bancos sean bien gestionados y ofrezcan mayor seguridad a los depositantes y a la economía en general, también es importante reconocer que estas prácticas se deben adaptar a las peculiaridades de cada país. En este sentido, conviene recordar las características que definen a la estructura financiera mexicana (v.g. la existencia de bancos universales, el escaso desarrollo de los mercados de valores, la escasa bancarización de la economía, la ausencia de una cultura financiera en la población), pues estas características influirán en los efectos finales de la adopción de dichas prácticas. Así, el reto inmediato para los responsables de la administración bancaria en México consistirá en hallar el equilibrio entre las especificidades nacionales y el ámbito de aplicación de las prácticas internacionales.

\section{Referencias}

ALLEN, Franklin y Anthony M. Santomero (1997), "The theory of financial intermediation", Journal of Banking y Finance 21(11-12), diciembre, pp. 1461-1485.

BANXICO y SHCP (2003), "Globalization: The role of institution-building in the financial sector-The case of Mexico", documento presentado en Globalization: The Role of Institution-Building in the Financial SectorG20 Finance Ministers and Central Bank Governors Meeting, organizado por G-20, BANXICO y la SHCP, octubre 26-27, 2003, Morelia, Michoacán. 
Antonio Ruiz Porras

Noemí Vásquez Quevedo

José Antonio Núñez Mora

BARTH, James R., Gerard Caprio y Ross Levine (2001a), "The regulation y supervision of banks around the world: A new database", Policy Research Paper 2588, World Bank, Washington.

(2001b), "Bank regulation y supervision: What works best?", Policy Research Paper 2765, World Bank, Washington.

-(1999), "Financial regulation y performance: Cross-country evidence", Policy Research Paper 2037, World Bank, Washington.

BECK, Thorsten, Asli Demirguc-Kunt y Ross Levine (2003), "Bank concentration and crises", NBER Working Paper 9921, National Bureau of Economic Research, Cambridge.

BENSTON, George J. y George G. Kaufman (1996), "The appropriate role of bank regulation", Economic Journal 106(436), mayo, pp. 688-697.

BESSIS, Joel (2002), Risk Management in Banking, $2^{\text {nd }}$ ed., Chichester, John Wiley \& Sons Inglaterra.

BIS (2004), Convergencia internacional de normas y medidas de capital: marco revisado, Basilea, Banco de Pagos Internacionales-BIS, Suiza.

BUBEL, Robert V. y Edward C., Skelton (2002), "Financial Globalization: Manna or Menace? The Case of Mexican Banking", Federal Reserve Bank of Dallas Southwest Economy, 9(1), enero-febrero, pp. 17-19.

CAPRIO, Gerard and Daniela Klingebiel (2002), "Episodes of systemic and borderline financial crises", World Bank Research Domestic Finance Data Sets, [en línea] Disponible en http://www.econ.worldbank.org

CLAESSENS, Stijn, Asli Demirguc-Kunt y Harry Huizinga (2001), "How does foreign entry affect domestic banking markets?", Journal of Banking and Finance, 25(5), mayo, pp. 891-911. 
Efectos de la globalización financiera en la administración

y regulación de riesgos bancarios en México

y Luc Laeven (2003), "What drives bank competition? Some international evidence", Policy Research Paper 3113, World Bank, Washington.

CNBV (2004a), "Disposiciones de carácter prudencial en materia de administración integral de riesgos aplicables a las instituciones de crédito", Diario Oficial de la Federación, 1 de julio.

CNBV (2004b), "Disposiciones de carácter general aplicables a la metodología de la calificación de la cartera crediticia de las instituciones de crédito", Diario Oficial de la Federación, 20 de agosto.

CORREA, Eugenia, Alicia Girón y Alma Chapoy (coord.) (2005), Consecuencias de la globalización, México, Miguel Ángel Porrúa, IIE - UNAM.

DAVIS ARZAC, Jonathan (2004), "El nuevo acuerdo de capital", documento presentado en el Seminario El Nuevo Acuerdo de Capital de Basilea: Retos y Oportunidades para las Américas; organizado por ASBA, FELABAN y CEMLA, julio 12-13,2004, México.

DOWD, Kevin (1996), "The case for financial laissez-faire", Economic Journal, 106(436), mayo, pp. 679-687.

DEMIRGUC-KUNT, Asli y Enrica Detragiache (1998), "The determinants of banking crises in developing and developed countries", IMF Staff Papers, 45(1), marzo, pp. 81-109.

--_egulations, market structure, institutions y the cost of financial intermediation", Journal of Money, Credit y Banking, 36(3), junio, pp. 593-622.

ESPARZA, Rogelio (2004), "Basilea II, una revolución disfrazada de regulación", documento presentado en el Second Public and Private Sector Conference on the New Basel Capital Accord of Financial Regulation, organizado por el Banco Interamericano de Desarrollo, enero 30, 2004, Washington D.C. 
Antonio Ruiz Porras

Noemí Vásquez Quevedo

José Antonio Núñez Mora

FREIXAS, Xavier y Jean-Charles Rochet (1997), Microeconomics of Banking, Cambridge, MIT Press, EUA.

y Anthony M. Santomero (2004), "An overall perspective on banking regulation", en S. Bhattacharya, A. Boot y A. Thakor. (eds.), Credit Intermediation and the Macroeconomy: Models and Perspectives, Oxford University Press, pp. 424-448, New York.

GAYTÁN, Alejandro y Christian A. Johnson (2002), "A review of the literature on Early Warning Systems for banking crises", Documento de trabajo 183, Banco Central de Chile, Santiago de Chile.

GIRÓN, Alicia (2002), Crisis financieras, Miguel Ángel Porrúa, México.

(coord.) (1992) Integración y globalización ¿antecedentes de un modelo de desarrollo?, IIE-UNAM - Siglo XXI, México.

y Noemí Levy (2005), Los bancos que perdimos, IIE - UNAM Facultad de Economía, UNAM, México.

GOODHART, Charles et al. (1998), Financial Regulation. Why, How y Where Now?, Routledge, Londres.

HABER, Stephen y Shawn E. Kantor (2003), "Getting privatization wrong: The Mexican banking system 1991-1993", documento presentado en la World Bank Conference on Bank Privatization in Low y Middle Income Countries, noviembre 23, 2003. Washington.

HEFFERNAN, Shelagh A. (1996), Modern Banking in Theory y Practice, Chichester, John Wiley \& Sons Ltd, Inglaterra.

HIRTLE, Beverly J. (1991), "Factors affecting the competitiveness of internationally active financial institutions", Federal Reserve Bank of New York Quarterly Review 16(1), primavera, pp. 38-51. 
Efectos de la globalización financiera en la administración

y regulación de riesgos bancarios en México

HUERTA, Arturo (1998), La globalización, causa de las crisis asiática y mexicana, Diana, México.

HUNTER, William C. y Stephen D. Smith (2002), "Risk management in the global economy: A review essay", Journal of Banking y Finance 26(2-3), marzo, pp. 205-221.

KAMINSKY, Graciela L. y Carmen M. Reinhart (1999), "The Twin Crises: The Causes of banking and Balance-of-Payments Problems", American Economic Review, 89(3), junio, pp. 473-500.

(1998) "Financial crises in Asia and Latin America: Then and now", American Economic Review, 88(2), mayo, pp. 444-448.

KPMG (2005) "Revisiones regulatorias" KPMG Menú de Servicios de FRM [en línea], disponible en http://www.kpmg.com.mx/servicios/aras_frm-revregulatorias.htm [1 de junio].

MÉNDEZ DEL RIO, Manuel A. (2003), "Basilea II y la gestión de entidades financieras: consideraciones estratégicas", Revista de Estabilidad Financiera, no. 4, mayo, pp. 103-128.

MISHKIN, Frederic S. (2005), "Is financial globalization beneficial?", NBER Working Paper 11891, National Bureau of Economic Research, Cambridge.

(2004), The Economics of Money, Banking y Financial Markets, $7^{\text {th }}$ ed., Addison Wesley, Boston.

MODIGLIANI, Franco y Merton H. Miller (1958), "The cost of capital, corporation finance y the theory of investment", American Economic Review, 48(3), junio, pp. 261-297.

NIGH, Douglas, Kang R. Cho y Suresh Krishnan (1986), "The role of location related factors in US banking involvement abroad: An empirical examination", Journal of International Business Studies, 17(3), septiembre, pp. 59-72. 
Antonio Ruiz Porras

Noemí Vásquez Quevedo

José Antonio Núñez Mora

ORTIZ MARTÍNEZ, Guillermo (1994), La reforma financiera y la desincorporación bancaria, Fondo de Cultura Económica, México.

ROSE, Peter S. (2002), Commercial Bank Management, $5^{\text {th }}$ ed., McGraw-Hill/ Irwin, New York.

ROJAS SUÁREZ, Liliana (2001a), "Rating banks in emerging markets", Working Paper 01-06, Institute for International Economics, Washington.

(2001b) "Can international capital standards strengthen banks in emerging markets?", Working Paper 01-10, Institute for International Economics, Washington.

RUIZ PORRAS, Antonio (2006), "Financial systems and banking crises: An assessment", Revista Mexicana en Economía y Finanzas [en prensa].

SAIDENBERG, Marc y Til Schuermann (2003), "The new Basel Capital Accord and questions for research", Wharton-Financial Institutions Center, mayo, Pennsylvania, WP 0314.

SCHOLTENS, Bert y Dick van Wensveen (2000), "A critique on the theory of financial intermediation", Journal of Banking y Finance 24(8), agosto, pp. 1243-1251.

SHENG, Andrew (1999) "The framework for financial supervision: macro y micro issues", in BIS Strengthening the Banking System in China: Issues y Experience, BIS policy papers, Vol. 7 Bank for International Settlements, Basilea, pp. 154-166.

STALLINGS, Barbara y Rogério Studart (2003), Financial Regulation and Supervision in Emerging Markets: The Experience of Latin America since the Tequila Crisis, Santiago, Chile, United Nations-ECLAC.

STIGLER, George J. (1971), "The theory of economic regulation", Bell Journal of Economics y Management Science, 2(1), primavera, pp. 3-21. 
Efectos de la globalización financiera en la administración

y regulación de riesgos bancarios en México

STIGLITZ, Joseph E. (2002), El malestar en la globalización, Taurus, México. (2004), Los felices noventa, Taurus, México.

ZIMMER, Steven A. y Robert N. McCauley (1991) "Bank cost of capital and international competition", Federal Reserve Bank of New York Quarterly Review, 15(3-4), invierno, pp. 33-59. @ 